\title{
Oral Re-Pigmentation After Depigmentation- A Short Review and Case Report
}

Rajesh Hosadurga*, Sunil Kumar Nettemu, Vijendra Pal Singh and Soumya Nettem

Department of Periodontics, Melaka Manipal Medical College, Melaka, Malaysia

*Corresponding autor: Rajesh Hosadurga, Department of Periodontics, Melaka Manipal Medical College, Jalan Batu Hampar, Bukit Baru, Melaka 75150 Melaka, Malaysia, Tel: +919886428859, +601837730789; E-mail: drsharaj@gmail.com

Recieved Date: April 13, 2017; Accepted Date: April 18, 2017; Published Date: April 28, 2017

Copyright: (c) 2017 Hosadurg R, et al. This is an open-access article distributed under the terms of the Creative Commons Attribution License, which permits unrestricted use, distribution, and reproduction in any medium, provided the original author and source are credited.

\begin{abstract}
Melanin is a pigment that contributes to our skin color. Hyperpigmentation where melanin is produced in excess quantity can cause significant esthetic problem. Facial aesthetics is affected by smile line. Gingiva is an integral component of facial esthetics. Hyperpigmentation in gingiva affects facial esthetics. Various surgical modalities have been employed to correct hyperpigmentation. But, repigmentation is seen few months post-surgery. But the intensity and degree varies. Considerable improvement in gingival esthetics can be successfully achieved. In the present case, hyperpigmentation was graded, scalpel technique was used for depigmentation, crown lengthening by gingivectomy and frenectomy was done to correct altered passive eruption and aberrant frenal attachment. Oral repigmentation was graded and followed up to 5 months. Significant improvement in aesthetics of maxillary and mandibular gingival esthetics was achieved.
\end{abstract}

Keywords: Altered passive eruption; Diastema; Frenum; Esthetics; Gingiva; Melanin hyperpigmentation

\section{Key Messages}

Gingival hyper pigmentation and short clinical crowns affect gingival esthetics. Depigmentation procedures help remove hyper pigmentation. Oral repigmentation does occur. But the intensity and severity will be less and provides better esthetics.

\section{Introduction}

Melanin pigmentation is a normal clinical characteristic of oral tissues. Several factors affect gingival pigmentation [1]. In individuals with high smile lines and excessive gingival display physiologic gingival hyperpigmentation causes esthetic problema [2]. The pigmentation indices is an objective method to classify and assess the efficacy of treatment $[3,4]$. Gingival depigmentation using scalpel was one of the first and popular method because of its cost effectiveness [5]. Gingival repigmentation is the reappearance of melanin pigmentation after a period of time after the treatment [6]. It depends on the type of surgical procedure. In scalpel technique $30 \%$ repigmentation was noted in 3 months [7]. Altered passive eruption is a condition wherein the relationship between the teeth, alveolar bone and surrounding soft tissues create an excessive gingival display and causes gummy smile. It has been classified into four stages (Table 1) [8]. It can cause esthetic problem and along with lip incompetence it can be a contributing factor for gingivitis [9]. Garber and Salama suggested two treatment options- Gingivectomy in Class1-Type A and Resective osseous surgery with apically displaced flap.

\section{Case Report}

A 22 year old female patient presented to the outpatient, department of Periodontics, Melaka-Manipal Medical College, Melaka with a complaint of black gums and small teeth. Short clinical crown and pigmented gingiva caused significant esthetic concern to the patient. She was systemically healthy, dark complexioned, non-smoker, non-alcoholic and not willing to undergo orthodontic treatment. Her only concern was dark gums (Figure 1).

\begin{tabular}{|l|l|}
\hline Condition & Treatment options \\
\hline Altered passive eruption Type IA & Gingivectomy \\
\hline Altered passive eruption Type IB & Flap with osseous resection \\
\hline Vertical maxillary excess degree 1 & $\begin{array}{l}\text { Orthodontics } \\
\text { Orthodontics \& Periodontics } \\
\text { Periodontics \& Restorative dentistry }\end{array}$ \\
\hline Vertical maxillary excess degree 2 & $\begin{array}{l}\text { Periodontics \& Restorative dentistry } \\
\text { Orthognathic surgery }\end{array}$ \\
\hline Vertical maxillary excess degree 3 & $\begin{array}{l}\text { Orthognathic surgery plus Periodontics } \\
\text { \& Restorative dentistry where } \\
\text { necessary. }\end{array}$ \\
\hline
\end{tabular}

Table 1: The classification of altered passive eruption and treatment options [8].

On clinical examination there was midline diastema with papillary penetrating aberrant frenum and tongue thrusting habit. There was false pocket of 4-5 $\mathrm{mm}$ in upper and lower anteriors with no clinical attachment loss. Only $50-60 \%$ of the anatomic crown was visible and dense melanin pigmentation was seen. Gingival pigmentation index by Kumar et al. [4] as it suited the clinical situation Score 3 was given from canine to canine in both maxillary and mandibular anteriors. There was generalized chronic inflammatory gingival enlargement. A diagnosis of chronic generalized inflammatory enlargement with Altered passive eruption Type IA was made. Initial therapy included Oral hygiene instructions, scaling and root planing and Re-evaluation of Phase I after 14 days. Informed consent was taken (Figure 2). 
Citation: Hosadurga R, Nettemu SK, Singh VP, Nettem S (2017) Oral Re-Pigmentation After Depigmentation- A Short Review and Case Report. Dentistry 7: 429. doi:10.4172/2161-1122.1000429

Page 2 of 3

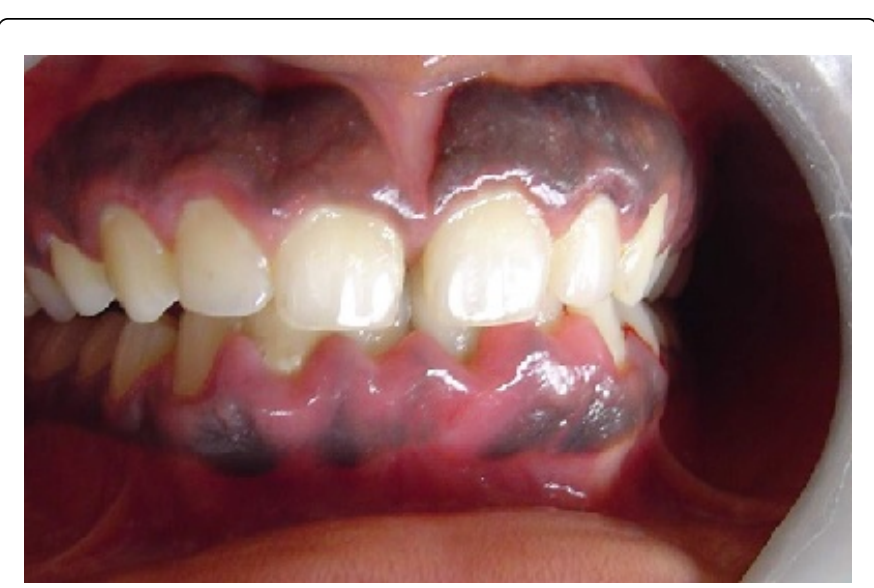

Figure 1: Preoperative photograph.

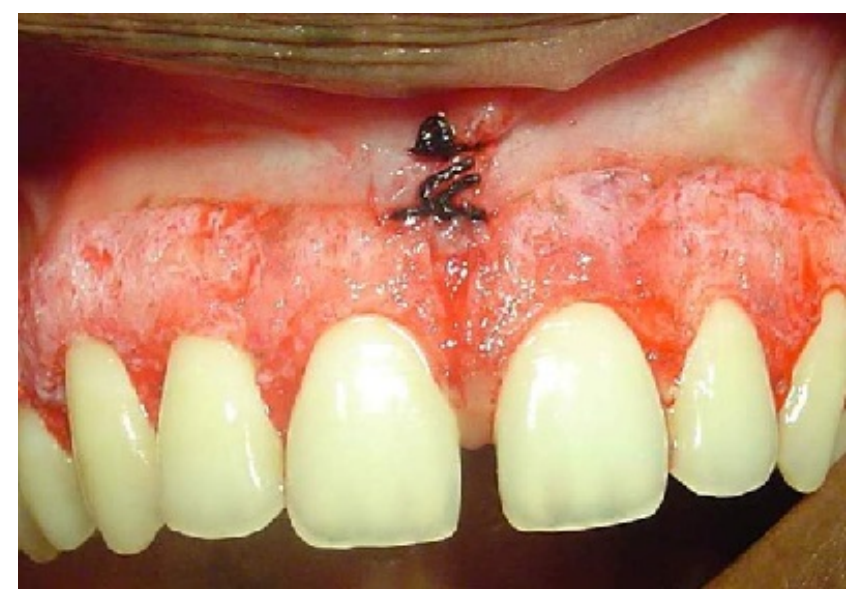

Figure 2: Depigmentation, crown lengthening and Frenectomy.

\section{Surgical Procedure}

\section{Crown lengthening procedure}

Gingivectomy was the procedure of choice as per guidelines for crown lengthening. Patient was anesthetized with $2 \%$ Lignocaine local anesthesia. Trans gingival probing was done to assess supra alveolar tissue dimensions. Pockets were marked with a Goldman-Fox pocket marker. Continuous external bevel incisions were placed with B.P. blade number 15 apical to the bleeding points. Pocket wall was excised (Figure 3).

\section{Gingival depigmentation}

Crown lengthening was followed with Sub epithelial excision procedure with No.15 surgical blade. Two vertical incisions were placed mesial and distal to the site of interest. Split- thickness flap was raised. Bleeding was controlled. The exposed site was covered with non - eugenol periodontal pack (Figure 4).

Maxillary labial frenectomy using rhomboidal incision prior to sub epithelial excision to remove the aberrant frenum and facilitate oral hygiene maintenance. Non- eugenol periodontal pack was placed. Analgesics (Diclofenac sodium $50 \mathrm{mg}$ was prescribed for two days) and $0.12 \%$ chlorhexidine was prescribed for 21 days.

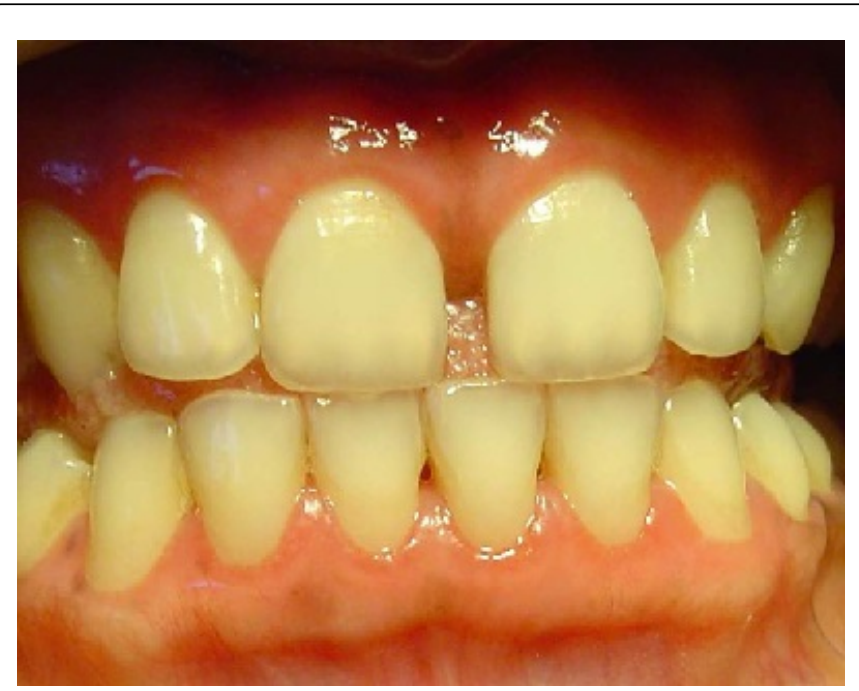

Figure 3: Post operative photograph after 2 months showing mild repigmentation (scorelas per Gingival pigmentation index).

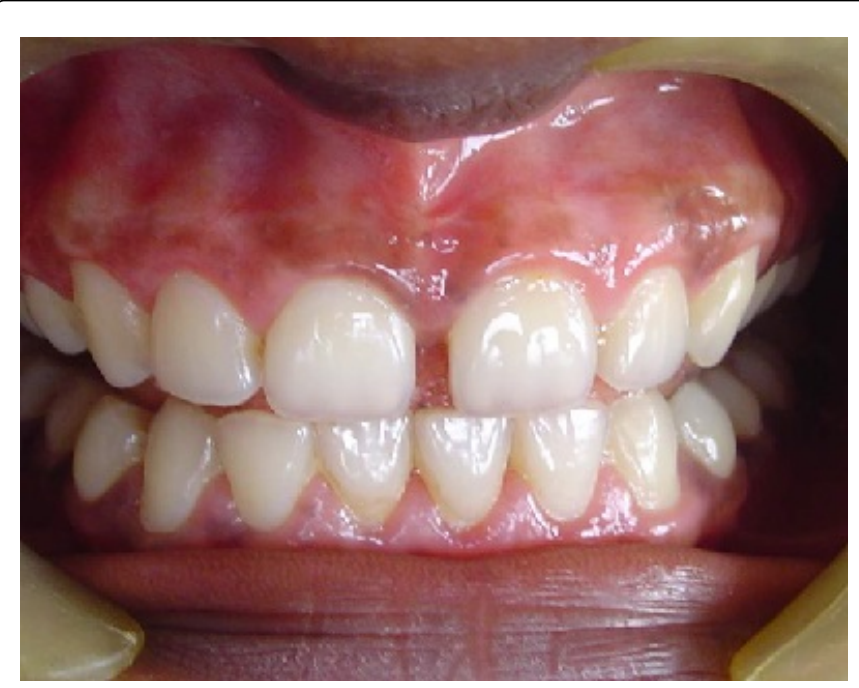

Figure 4: Post-operative photograph showing (score 2 as per Gingival pigmentation index) repigmentation after 5 months.

Oral hygiene instructions were given. Patient was recalled after 1 week \& periodontal pack and sutures were removed. Oral hygiene instructions were reinforced. Patient was recalled every month post surgically for re-evaluation. A 5-month follow up was done. We observed for re pigmentation and when it appeared it was quantified using Gingival pigmentation index (GPI). Patient did not opt for treatment of diastema closure.

\section{Results}

The healing was uneventful. Patient did not report of pain, postoperative bleeding or ulcer at the surgical site. No scarring was noted. 
Patient was satisfied with the initial results. There was no repigmentation during the initial healing period. We noticed re pigmentation at 2 months post surgically. At the end of 5 months period score 2 pigmentation was noticed. But the intensity had reduced remarkably. The esthetic appearance improved significantly. Patient moved from the city and further follow up could not be done.

\section{Discussion}

Physiologic melanin hyper pigmentation can cause significant esthetic concern for the patients. When it's combined with chronic gingival enlargement, Type $1 \mathrm{~A}$ altered passive eruption and maxillary aberrant frenal attachment, it poses a challenge for the periodontist to obtain optimal esthetics. As per the guidelines proposed by Garber and Salama [10], the crown lengthening was done using gingivectomy. Rossi et al. reported that altered passive eruption had familial trait [11]. In this case patient was not aware of family history. We achieved good amount of crown exposure and adequate attached gingiva with gingivectomy procedure and it remained stable for 5 months.

There are several techniques with varying results to treat gingival hyper pigmentation. We chose Conventional scalpel technique. In this procedure the gingival epithelium with a layer of connective tissue beneath it is removed [11]. This procedure is simple, effective and one of the most cost effective treatment [12]. Healing occurs by secondary intention. However, there might be post-operative complications like bleeding and infection. Hence, the exposed connective tissue was covered with periodontal pack.

Aberrant frenal attachment in the maxilla created a functional problem like inadequate width of gingiva, midline diastema and difficulty in maintaining proper oral hygiene because of interference of frenum during tooth brushing. Frenectomy can be done using conventional scalpel technique, lasers or electro surgery. Scalpel technique if done with proper precautions is highly predictable and cost effectiv [13]. We did not encounter any complication during or post frenectomy. Healing was uneventful.

Oral repigmentation refers to the clinical reappearance of melanin pigment following a period during which clinically pigmented oral tissues were depigmented. Dummet et al. noticed repigmentation as early as 33 days. They noticed $100 \%$ repigmentation in dark complexioned individuals [14]. Kaur et al. noted that the melanin pigmentation score decreased from 2.40 to 0.93 . They employed Dummett-Gupta oral pigmentation index.

It has also been noticed that repigmentation in the anterior region is more than the posteriors [15]. However, in our case we noted repigmentation at the end of 2 months as small flecks and by the end of 5 months it increased to small areas of repigmentation was seen. The gingival pigmentation score decreased from 3 to 2 according to Gingival pigmentation index. But the intensity was less and it was similar to other studies [15].

The mechanism of repigmentation is not clearly understood. It has been hypothesized that the melanocytes from the adjacent pigmented tissues migrate to the treated area and cause repigmentation [16]. It has been hypothesized that the rate of melanin formation is higher in dark complexioned people than fair complexioned [17]. The gingival pigmentation is more in the anteriors than posteriors and have been attributed to sunlight exposure [18].

\section{Conclusion}

Physiologic gingival hyperpigmentation and short clinical crown was causing esthetic problem in the reported case. Surgical depigmentation, crown lengthening and frenal correction caused considerable improvement in the esthetics. Gingival repigmentation occurred at 2 months and increased gradually till 5 months. However, the intensity was considerably less.

\section{References}

1. Dummett CO, Barens G (1971) Oromucosal pigmentation: An updated literary review. J Periodontol 42: 726-736.

2. Hanaa M, Shenawy EL, Sherine AN, Zaky AA, Mohamed A (2015) Treatment of Gingival Hyperpigmentation by Diode Laser for Esthetical Purposes. Open Access Maced J Med Sci 15: 447-454.

3. Peeran SW, Ramalingam K, Peeran SA, Altaher OB, Alsaid FM (2014) Gingival pigmentation index proposal of a new index with a brief review of current indices. Eur J Dent 8: 287-290.

4. Kumar S, Bhat SG, Bhat MK (2012) Development in techniques for gingival depigmentation. An update. Indian J Dent 3: 213-221.

5. Patil KP, Joshi V, Waghmode V, Kanakdande V (2015) Gingival depigmentation: A split mouth comparative study between scalpel and cryosurgery. Contemporary Clinical Dentistry. 6: S97-S101.

6. Sedeh SA, Badihi S, Esfahaniyan V (2014) Comparison of recurrent rate of gingival pigmentation after treatment by liquid nitrogen and cryoprob in 18 months follows-up. Dental Research Journal 11: 592-598.

7. Kaur H, Jain S, Sharma RL (2010) Duration of reappearance of gingival melanin pigmentation after surgical removal- A clinical study. Journal of Indian Society of Periodontology 14: 101-105.

8. Rossi R, Brunelli G, Piras V, Pilloni A (2014) Altered Passive Eruption and Familial Trait: A Preliminary Investigation. Int J Dent 5: 92.

9. Biniraj KR, Janardhanan M, Sunil MM, Sagir M, Hariprasad A, et al. (2015) A Combined Periodontal - Prosthetic Treatment Approach to Manage Unusual Gingival Visibility in Resting Lip Position and Inversely Inclined Upper Anterior Teeth: A Case Report with Discussion. J Int Oral Health 7: 64-67.

10. Garber DA, Salama MA (1996) The aesthetic smile: diagnosis and treatment. Periodontol 11: 18-28.

11. Rossi R, Brunelli G, Piras V, Pilloni A (2014) Altered Passive Eruption and Familial Trait: A Preliminary Investigation. Int J Dent 2: 92.

12. Roshna T, Nandakumar K (2005) Anterior esthetic gingival depigmentation and crown lengthening: Report of a Case. J Contemp Dent Pract 6: 139-147.

13. Devishree, Gujjari SK, Shubhashini PV (2012) Frenectomy: A Review with the Reports of Surgical Techniques. J Clin Diagn Res 6: 1587-1592.

14. Dummett CO, Bolden TE (1963) Post-surgical clinical repigmentation of the gingivae. J Oral Surg Oral Med Oral Path 16: 353-365.

15. Kaur H, Jain S, Sharma RL (2010) Duration of reappearance of gingival melanin pigmentation after surgical removal- A clinical study. J Indian Soc Periodontol 14: 101-105.

16. Perlmutter S, Tal H (1986) Repigmentation of the gingiva following surgical injury. J Periodontol 57: 48-50.

17. Billingham RE (1949) Dendritic cells in pigmented human skin. J Anat 83: 109-115.

18. Raut RB, Baretto MA, Mehta FS, Sanjana MK, Shourie KL (1954) Gingival pigmentation: Its incidence amongst the Indian adults. JAIDA: 26: $9-10$ 